ONLINE MUTATION REPORT

\title{
Low frequency of BMPR2 mutations in a German cohort of patients with sporadic idiopathic pulmonary arterial hypertension
}

\author{
R Koehler*, E Grünig*, M W Pauciulo*, M M Hoeper, H Olschewski, H Wilkens, M Halank, \\ J Winkler, R Ewert, H Bremer, S Kreuscher, B Janssen, W C Nichols
}

J Med Genet 2004;41:e127 (http://www.jmedgenet.com/cgi/content/full/41/12/e127). doi: 10.1136/jmg.2004.023101

listan diopathic pulmonary arterial hypertension (IPAH; formerly known as primary pulmonary hypertension, $\mathrm{PPH}$ ) is a rare disorder characterised by pulmonary vascular proliferation and remodelling resulting in loss of patency of the pulmonary arteries. This leads to sustained elevation of pulmonary artery pressures with subsequent progressive right heart failure and often death. ${ }^{1-3}$ While the majority of cases $(>90 \%)$ have no known family history of the disease, $\sim 6 \%$ of the cases are known to be familial and are inherited in an autosomal dominant manner with markedly reduced penetrance. ${ }^{4}$ In previous studies, linkage analysis identified a familial IPAH locus on chromosome $2 \mathrm{q}_{33} .^{56}$ Subsequent heterozygous germline mutations in the bone morphogenetic protein receptor, type II (BMPR II) gene (BMPR2) were identified in at least $50 \%$ of familial cases. ${ }^{7-9}$ BMPR-II is a member of the transforming growth factor- $\beta$ (TGF- $\beta$ ) receptor superfamily signalling pathway, which is critical in both cell differentiation and cell growth mediated through transcriptional regulation. ${ }^{10}{ }^{11}$ Interestingly, germline mutations were also identified in $26-40 \%$ of sporadic cases. ${ }^{12}{ }^{13}$ This study was performed to establish the frequency of BMPR2 mutations in a different population of patients with sporadic IPAH.

\section{METHODS \\ Patients}

Between March 2002 and January 2004, 99 consecutive nonrelated patients $>20$ years of age with IPAH and negative family history were evaluated. In all cases, diagnosis of IPAH was made by experienced and specialised cardiologists or pulmonologists according to WHO criteria. ${ }^{14}$ Other causes of pulmonary hypertension such as illicit drug abuse or anorectic drug use were excluded by careful medical history evaluation. Underlying heart and lung diseases (recurrent pulmonary embolism, connective tissue disease, obstructive or restrictive lung disease) and HIV infection were excluded by a cascade of clinical examinations including laboratory tests, arterial blood gas analysis, chest $x$ ray, pulmonary function tests, echocardiography, ventilation perfusion scanning, chest computed tomography, pulmonary angiography (when indicated), and cardiac catheterisation (table 1). EDTA blood samples were collected for genetic analysis in all patients. The study protocol was approved by the Ethics Committee of the Medical Faculty of the University of Heidelberg and written informed consent was given by each patient.

\section{BMPR2 mutation analysis}

Mutation analysis of the BMPR2 coding sequence and intron/ exon boundaries was performed in two independent laboratories using two different detection methods. In one laboratory $(\mathrm{RK}, \mathrm{BJ})$ the entire BMPR2 coding sequence and all intron/exon boundaries were analysed by dHPLC (WAVE, Transgenomic, Omaha, NE, USA). Primer sequences used for

\section{Key points}

- Idiopathic pulmonary arterial hypertension (IPAH) is a rare progressive disorder in which elevated pulmonary artery pressure, in the absence of secondary causes, leads to right heart failure and death. Mutations of the bone morphogenetic protein receptor type II gene (BMPR2) have been identified in both familial and sporadic cases.

- This study, the first to investigate the frequency of BMPR2 mutations in a German cohort, analysed 99 patients with sporadic IPAH. BMPR2 mutations were identified in only 11 cases ( $11 \%)$.

- These data suggest that BMPR2 mutations may be less frequent than previously reported in sporadic IPAH and that the role of BMPR2 mutations in the sporadic phenotype may have been overestimated.

dHPLC are listed in table 2. Genomic DNA samples of all 99 patients were analysed using at least two different dHPLC protocols per PCR fragment according to the manufacturer's instructions. Any fragments demonstrating aberrant properties were subjected to DNA sequence analysis. In the second laboratory (MWP, WCN) the entire coding region including intron/exon boundaries of the BMPR2 gene was investigated by direct sequencing (BigDye Terminator version 2.0, Applied Biosystems) using an ABI 3700 DNA Analyzer (Applied Biosystems, Foster City, CA, USA). The PCR conditions and primer data are available at http://www.med.uni-heidelberg.de/humangen/ger/humgen/pph-scl.htm. The analyses were conducted concurrently in a blinded fashion and the results were compared only after analyses were completed by each laboratory.

\section{RT-PCR}

CDNA analysis was performed by RT-PCR to determine the significance of the potential splice-site mutation. RNA was prepared from peripheral blood leukocytes using TRIzol reagent, as described by the manufacturer (Life Technologies, Carlsbad, CA, USA). Total RNA $(1 \mu \mathrm{g})$ was reverse transcribed using random hexamer primers (Pharmacia Biotech Piscataway, NJ, USA) and 200 units of MMLV reverse transcriptase (SuperScript, Life Technologies) for $\mathrm{l} \mathrm{h}$ at $42^{\circ} \mathrm{C}$. RT-PCR products were obtained using region specific

Abbreviations: IPAH, idiopathic pulmonary arterial hypertension; PPH, primary pulmonary hypertension; TGF- $\beta$, transforming growth factor- $\beta$; UV, unclassified variant 
Table 1 Clinical data of the sporadic IPAH patients

\begin{tabular}{|c|c|c|c|c|c|c|c|c|c|}
\hline Patient & $\begin{array}{l}\text { Current age (SD), } \\
\text { years }\end{array}$ & $\begin{array}{l}\text { Sex, } \\
m / f\end{array}$ & $\begin{array}{l}\text { PAP (SD), } \\
\mathrm{mm} \mathrm{Hg}\end{array}$ & $\begin{array}{l}\mathrm{PaO}_{2} \text { (SD), } \\
\mathrm{mm} \mathrm{Hg}\end{array}$ & $\begin{array}{l}\text { PVR (SD), dyn s } \\
\mathrm{cm}^{-5 *} / \mathrm{M}^{2}\end{array}$ & $\begin{array}{l}\mathrm{Cl}(\mathrm{SD}), \\
\mathrm{l} / \mathrm{min} / \mathrm{M}^{2}\end{array}$ & $\begin{array}{l}\mathrm{CO}(\mathrm{SD}), \\
\mathrm{l} / \mathrm{min}\end{array}$ & $\begin{array}{l}\text { SAP (SD), } \\
\text { mm Hg }\end{array}$ & $\begin{array}{l}\mathrm{SvO}_{2},(\mathrm{SD}), \\
(\%)\end{array}$ \\
\hline $\mathrm{n}=99+$ & $46(14)$ & $29 / 70$ & $55(15)$ & $63(14)$ & 1205 (563) & $1.96(0.71)$ & $3.50(1.13)$ & $90(12)$ & 59 (11) \\
\hline
\end{tabular}

tNYHA class: | 2\%; || 17.\%; ||I 67\%; IV 14\%.

Values are mean (SD). Cl, cardiac index; $\mathrm{CO}$, cardiac output; $\mathrm{PaO}_{2}$, alveolar partial pressure of oxygen; PAP, pulmonary arterial mean pressure; PVR, pulmonary vascular resistance; $\mathrm{SAP}$, systemic arterial mean blood pressure; $\mathrm{SvO}_{2}$, venous haemoglobin oxygen saturation.

A

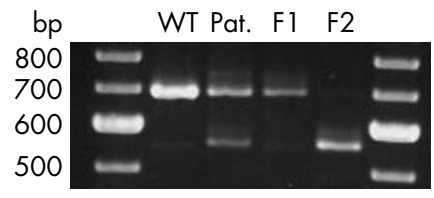

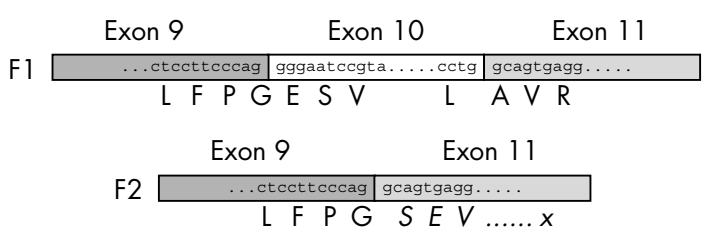

Figure 1 (A) CDNA analysis of patient MHH10 (Pat.) in comparison with wildtype CDNA (WT). Patient MHH10 shows two different PCR fragments, one (F1) similar to the wildtype amplicon and the other (F2) below $600 \mathrm{bp}$. Both fragments were re-amplified after gel extraction (lanes F1 and F2) and sequenced. (B) Schematic illustration of exon splicing in both fragments (F1, F2) based on the sequencing results. Fragment F1 demonstrated the wildtype cDNA sequence with a predicted normal amino acid sequence as indicated. Fragment F2 demonstrated a deletion of exon 10 and predicts a frameshift at the protein level illustrated by italicised letters.

primers (sequences available on request) and subsequently analysed by dye terminator sequencing.

\section{RESULTS}

Heterozygous germline BMPR2 mutations were identified in 11 of the 99 (11.1\%; 95\% confidence interval: 5.7 to $19 \%$, calculated by exact approximation) sporadic IPAH patients (table 3). We identified five novel nonsense mutations (E31X, R321X, Q450X, W466X, Q495X), one known missense mutation (R49lW), ${ }^{7}$ and one known nonsense mutation $(\mathrm{R} 584 \mathrm{X}){ }^{8}$ Additionally, we identified two novel splice site mutations. The genomic DNA of patient K377lA had a substitution at the first nucleotide of intron 8 (IVS8+lG $\rightarrow$ T). No RNA was available to test the consequence of this splice mutation on the protein level. The genomic DNA of patient MHHIO demonstrated a change at the third nucleotide of intron 10 (IVS10+3A $\rightarrow$ T), which leads to a deletion of exon 10. Deletion of exon 10 results in the frameshift G426fs $(+27)$ (fig 1).

In two cases we identified novel frameshift mutations, both predicted to result in premature termination of the
BMPR-II peptide. In the first case, K4690A, we found a 4 bp deletion (c.1313-1316 del CAGA) in exon 10 that generates a stop codon 35 amino acids downstream of the mutation. In patient MHH52, we detected a 1 bp insertion (c.1388 insA), which results in a stop codon six amino acids downstream of the mutated codon E464.

We detected an unclassified variant (UV) in patient MHH07 which results in the substitution of glutamic acid for glycine at codon 386 (fig 2). It seems likely that the substitution of glycine for glutamic acid in the kinase domain of BMPR-II, a change from an acidic to an aliphatic amino acid, has functional relevance. In the absence of functional data, however, the substitution E386G has been characterised as a UV.

Analysis of parental DNA samples for the E3IX mutation detected in patient K4518A confirmed the mutation in the non-symptomatic mother. No parental DNA was available for any of the other cases in which BMPR2 mutations were identified. All results were confirmed by both laboratories; each mutation was detected by both of the methods described above.

Table 2 Primers for BMPR2 mutation scanning by DHPLC

\begin{tabular}{|c|c|c|}
\hline Exon & Forward primer & Reverse primer \\
\hline 1 & 5' -GCA TGA AAG CTC TGC AGC TA- 3' & 5' -ATT TCC CTG GAA GGC ATG G- 3' \\
\hline 2 & 5' -GTC ATT TGG ATA AGA CAA AG- 3' & $5^{\prime}$-TाT AAC ATA CTC CCA TGT CC- 3' \\
\hline 3 & 5' -TAG CCT ACA CGT ACT CTC AC- 3' & $5^{\prime}$-CCT GGC TTC AAC CTT GAA TG- 3' \\
\hline 4 & 5' -GGG TAC AGC CTT TCT AAA GG- 3' & 5' -GAT ACT ATT GAG GCT GGG TG- 3' \\
\hline 5 & 5' -GCT GCT AAT CTT TCT GCA GC- 3' & 5' -GAA TGA AGT CAC TGT TCC AG- 3' \\
\hline 6 & 5' -CAG AGA GCT GTA GCA TTC TG- 3' & 5' -AAG TGA TCC ACC TGC CT AG- $3^{\prime}$ \\
\hline 7 & 5' -CGC ATT TIT TCC TCT ATA- $3^{\prime}$ & $5^{\prime}$-TGC ATT TCA TGC TGA ATC TाT C- $3^{\prime}$ \\
\hline 8 & 5' -GCA GAA AAA TAA TAC TAC TTC TAT A- 3' & $5^{\prime}$-GAT GTT TIT AAT TAA ATT ATC ATT TC- 3' \\
\hline 9 & 5' -AGA ATA TGC TAC GTT CTC TC- 3' & $5^{\prime}$-ACA CTA GAT AGC AAT GAA CTA AAG G- 3' \\
\hline 10 & 5' -GCC TGA AGG GGA TGA AAA A- 3' & 5' -GCC ATT AGG CAA CTC CAA AA- 3' \\
\hline 11 & 5' -CCT CAT GTG GTA AAC TGA AAA GC- 3' & $5^{\prime}$-TGC ACT TGT ACC AAA CAA AAA TG- 3' \\
\hline $12-1$ & 5' -AAA TIT GGA GAG ACA GTT TGT CA- 3' & $5^{\prime}$-TTC ATC TTG GTA TGG CAT CTC- $3^{\prime}$ \\
\hline $12-2$ & 5' -AGC AAG CAC AAG CTC GAA TC- 3' & 5' -AGT CCT GCT GTC CAG TTG CT- 3' \\
\hline $12-3$ & 5' -TCT AGC TTG CTT TAC CCA CT- $3^{\prime}$ & 5' -AGC ATG GGA GTT AAC ACT GT- 3' \\
\hline $12-4$ & 5' -ACC TCA TGT GGT GAC AGT CA- 3' & 5' -AT GGA ATT AGT TCG GCC AC- 3' \\
\hline $12-5$ & 5' -ATT CCA GTC CTG ATG AGC AT- 3' & 5' -AGT TAT TTA AAT GGC CCC AA- $3^{\prime}$ \\
\hline 13 & 5' -TTA CAT CCC TTA CCC GTT AT- $3^{\prime}$ & 5' -TA AAG CAA GTC गाT GTT GC- 3' \\
\hline
\end{tabular}




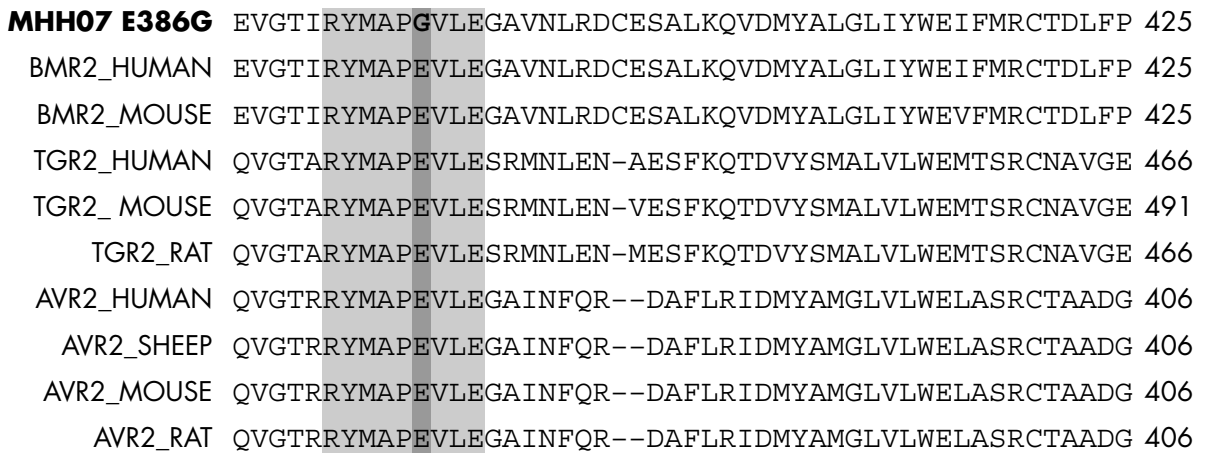

Figure 2 Amino acid alignment of type II TGF- $\beta$ superfamily receptors surrounding E386 in BMPR-II. Patient MHH07 has an amino acid substitution E386G (dark grey), which is located in the kinase domain of the BMPR-II protein. The alignment showed a wholly conserved region of nine amino acids (light grey) in different mammalian species (mouse, human, rat, sheep) for several type II receptors. AVR2, activin receptor type II; BMR2, bone morphogenetic protein receptor type II; TGR2, TGF- $\beta$ receptor type II.

\section{DISCUSSION}

Our findings of 11 heterozygous germline BMPR2 mutations in 99 sporadic IPAH patients (11\%) are significantly different from those of previously published studies. Thomson et al determined the frequency of BMPR2 mutations in a cohort of 50 sporadic IPAH patients and found germline mutations in 13 of the patients $(26 \%) .{ }^{12}$ Their conclusion was that germline mutations predispose to sporadic IPAH as they do in the familial form of the disease. Morisaki and colleagues found 12 mutations in a group of 30 Japanese patients $(40 \%) .{ }^{13}$ They hypothesised that some of these cases might actually be familial in nature, since most of their samples were from adults for whom no parental DNA was available. Our findings of only an $11 \%$ mutation rate in our cohort of 99 IPAH patients is significantly different from both the studies by Thompson et al $(\mathrm{p}=0.0196)$ and Morisaki et al $(p=0.0003)$. There are several potential explanations for this discrepancy. The first is population differences between the three cohorts. Regarding the study by Thomson et al, both our cohort and theirs are of Northern European descent. Despite this seemingly common ancestry, it is possible that different environmental factors and lifestyles could affect the penetrance and fitness of BMPR2 mutations as well as the phenocopy rate. In comparison to the study by Morisaki et al, the population difference is more pronounced in that their cohort is of Japanese ancestry. Therefore, genetic differences affecting penetrance of BMPR2 mutations between the two populations may also play a role. Second, the smaller sample size of both the Thomson et al and the Morisaki et al studies introduces the potential for overestimation of the prevalence of BMPR2 mutations in sporadic IPAH due to sampling error. Third, patient recruitment differences may have occurred between the three studies. Any other causes of pulmonary hypertension were thoroughly excluded in our cohort. Finally, to ensure that no mutations were missed in our patients due to low grade mosaicism or sequencing artefacts, two different methods were used in two independent laboratories: direct sequencing and dHLPC. However, it cannot be ruled out in any of the three studies that undetected gene rearrangements, large deletions, insertions, or intronic mutations in the BMPR2 gene are responsible for the clinical phenotype in those patients for whom no mutations were identified. Thus, we conclude that the disparity between the estimated frequencies of mutations in the three studies is not due to differences in methodology.

Recent studies have tried to determine the role of BMPR2 in the pathogenesis of pulmonary arterial hypertension (PAH). Atkinson and coworkers reported a reduced expression of $B M P R 2$ in lung tissue in all patients with PAH. ${ }^{15}$ Most remarkable was the reduction in expression to far below the expected $50 \%$ in patients with a BMPR2 mutation. Neither haploinsufficiency nor a dominant negative effect, both previously suggested to explain the pathogenic outcome of dominant BMPR2 mutations, ${ }^{4}$ can explain this phenomenon. Geraci and colleagues have used microarray analysis to characterise the gene expression pattern in IPAH patients. ${ }^{16}$ Interestingly, comparison of expression patterns could be used to distinguish between sporadic IPAH and familial

Table 3 BMPR2 mutations and unclassified variants (UV) identified in sporadic IPAH patients

\begin{tabular}{|c|c|c|c|c|c|}
\hline No & Patient ID & Exon & Mutation type & Nucleotide change* & Amino acid change $\dagger$ \\
\hline 1 & K4518A & 2 & Nonsense & c. $91 \mathrm{G} \rightarrow \mathrm{T}$ & E31X \\
\hline 2 & K5429A & 7 & Nonsense & c.961 C $\rightarrow T$ & $\mathrm{R} 321 \mathrm{X}$ \\
\hline 3 & K3771A & 8 & Donor splice & IVS8 $+1 \mathrm{G} \rightarrow T$ & ND \\
\hline 4 & $\mathrm{MHH} 10$ & 10 & Donor splice & $\mathrm{IVS} 10+3 \mathrm{~A} \rightarrow \mathrm{T}$ & G426fs(+27) \\
\hline 5 & K4690A & 10 & Frameshift & c. $1313-1316$ del CAGA & $\mathrm{T} 438 \mathrm{fs}(+35)$ \\
\hline 6 & МHHO9 & 10 & Nonsense & c. $1348 \mathrm{C} \rightarrow \mathrm{T}$ & Q450X \\
\hline 7 & MHH52 & 10 & Frameshift & c. $1388-1389$ insA & $\mathrm{E} 464 \mathrm{fs}(+6)$ \\
\hline 8 & K5943A & 10 & Nonsense & c. $1397 \mathrm{G} \rightarrow \mathrm{A}$ & W466X \\
\hline 9 & K6361A & 11 & Missense & c. $1471{\mathrm{C} \rightarrow \mathrm{T}^{7}}^{\circ}$ & R491W \\
\hline 10 & K5590A & 11 & Nonsense & c. $1483 \mathrm{C} \rightarrow \mathrm{T}$ & Q495X \\
\hline 11 & MHHI 8 & 12 & Nonsense & c. $1750 \mathrm{C} \rightarrow \mathrm{T}^{8}$ & R584X \\
\hline 12 & MHH07 & 9 & UV (missense) & c. $1157 \mathrm{~A} \rightarrow \mathrm{G}$ & E386G \\
\hline
\end{tabular}

*Nucleotide numbers are according to published cDNA, with the A of the ATG designated as +1 . †Frameshifts are denoted with the amino acid, position, and number of amino acids until new stop codon. 
IPAH. They conclude that sporadic and familial IPAH are mechanistically distinct. Taken together, both the published expression data and our mutation data suggest that while reduction of BMPR2 expression is common in pulmonary hypertension patients, additional factors other than germline BMPR2 mutations may lead to the development of sporadic IPAH.

Although BMPR2 plays an important role in the pathogenesis of IPAH, our data indicate that in most cases of sporadic IPAH BMPR2 mutations are not the primary cause of the disease. However, identification of individuals with BMPR2 mutations could enable more accurate risk assessment in other family members. Therefore, despite the low mutation frequency in sporadic IPAH, genetic screening for germline BMPR2 mutations may be warranted.

\section{ACKNOWLEDGEMENTS}

We especially thank the clinicians in the following German study centres: Department of Pneumology, University of Hannover; Department of Pneumology, University of Giessen; Department of Pneumology, University of Homburg; Department of Pneumology, University of Dresden; Department of Pneumology, University of Leipzig; Department of Pneumology, University of Greifswald; and Department of Pneumology, University of Freiburg for their kind cooperation with this ongoing study.

\section{ELECTRONIC-DATABASE INFORMATION}

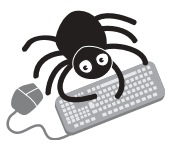

The PCR conditions and primer data mentioned in this study are available at $\mathrm{http}: / / \mathrm{ww} w$.med.uni-heidelberg.de/humangen/ger/humgen/pph-scl.htm.

\section{Authors' affiliations}

R Koehler, B Janssen, Institute of Human Genetics, University of Heidelberg, Heidelberg, Germany

E Grünig, S Kreuscher, Department of Internal Medicine III, University of Heidelberg, Heidelberg, Germany

M W Pauciulo, W C Nichols, Division of Human Genetics, Cincinnati Children's Hospital Medical Center, Cincinnati, OH, USA

M M Hoeper, Department of Pneumology, University of Hannover, Hannover, Germany

H Olschewski, Department of Pneumology, University of Giessen, Giessen, Germany

H Wilkens, Department of Pneumology, University of Homburg, Homburg, Germany

M Halank, Department of Pneumology, University of Dresden, Dresden, Germany

J Winkler, Department of Pneumology, University of Leipzig, Leipzig, Germany

R Ewert, Department of Pneumology, University of Greifswald, Greifswald, Germany

H Bremer, Department of Pneumology, University of Freiburg, Freiburg, Germany

The study was funded by the University of Heidelberg and the National Institutes of Health (HL61997).
Conflict of interest: none declared.

*These authors contributed equally to this study.

Correspondence to: Dr William C Nichols, Division of Human Genetics, Cincinnati Children's Hospital Medical Center, 3333 Burnet Avenue,

1469 TCHRF, Cincinnati, OH 45229, USA; bill.nichols@cchmc.org

Revised version received 15 July 2004

Accepted for publication 16 July 2004

\section{REFERENCES}

1 Gaine SP, Rubin $\mathrm{U}$. Primary pulmonary hypertension. Lancet 1998;352(9129):719-25.

2 Gaine S. Pulmonary hypertension. JAMA 2000;284(24):3160-8.

3 Rich S, Dantzker DR, Ayres SM, Bergofsky EH, Brundage BH, Detre KM, Fishman AP, Goldring RM, Groves BM, Koerner SK. Primary pulmonary hypertension. A national prospective study. Ann Intern Med 1987; 107(2):216-23.

4 Runo JR, Loyd JE. Primary pulmonary hypertension. Lancet 2003:361(9368):1533-44.

5 Nichols WC, Koller DL, Slovis B, Foroud T, Terry VH, Arnold ND, Siemieniak DR, Wheeler L, Phillips JA III, Newman JH, Conneally PM, Ginsburg D, Loyd JE. Localization of the gene for familial primary pulmonary hypertension to chromosome 2q31-32. Nat Genet 1997; 15(3):277-80

6 Morse JH, Jones AC, Barst RJ, Hodge SE, Wilhelmsen KC, Nygaard TG. Mapping of familial primary pulmonary hypertension locus (PPHI) to chromosome 2q31-q32. Circulation 1997;95(12):2603-6.

7 Deng Z, Morse JH, Slager SL, Cuervo N, Moore KJ, Venetos G, Kalachikov S, Cayanis E, Fischer SG, Barst RJ, Hodge SE, Knowles JA. Familial primary pulmonary hypertension (gene $\mathrm{PPH} 1$ ) is caused by mutations in the bone morphogenetic protein receptor-II gene. Am J Hum Genet 2000;67(3):737-44

8 Machado RD, Pauciulo MW, Thomson JR, Lane KB, Morgan NV, Wheeler L, Phillips JA III, Newman J, Williams D, Galie N, Manes A, McNeil K, Yacoub M, Mikhail G, Rogers P, Corris P, Humbert M, Donnai D, Martensson G, Tranebjaerg L, Loyd JE, Trembath RC, Nichols WC. BMPR2 haploinsufficiency as the inherited molecular mechanism for primary pulmonary hypertension. Am J Hum Genet for primary pulmonar
$2001 ; 68(1): 92-102$.

9 Lane KB, Machado RD, Pauciulo MW, Thomson JR, Phillips JA III, Loyd JE, Nichols WC, Trembath RC. Heterozygous germline mutations in BMPR2, encoding a TGF- $\beta$ receptor, cause familial primary pulmonary hypertension. The International PPH Consortium. Nat Genet 2000;26(1):81-4.

10 Massague J, Wotton D. Transcriptional control by the TGF- $\beta /$ Smad signaling system. EMBO J 2000;19(8): 1745-54.

11 Massague J, Blain SW, Lo RS. TGF- $\beta$ signaling in growth control, cancer, and heritable disorders. Cell 2000;103(2):295-309.

12 Thomson JR, Machado RD, Pauciulo MW, Morgan NV, Humbert M, Elliott GC, Ward K, Yacoub M, Mikhail G, Rogers P, Newman J, Wheeler L, Higenbottam T, Gibbs JS, Egan J, Crozier A, Peacock A, Allcock R, Corris P, Loyd JE, Trembath RC, Nichols WC. Sporadic primary pulmonary hypertension is associated with germline mutations of the gene encoding BMPR-II, a receptor member of the TGF- $\beta$ family. J Med Genet 2000;37(10):741-5.

13 Morisaki H, Nakanishi N, Kyotani S, Takashima A, Tomoike H, Morisaki T. BMPR2 mutations found in Japanese patients with familial and sporadic primary pulmonary hypertension. Hum Mutat 2004;23:632.

14 Rubin L. Primary pulmonary hypertension. Chest 1993;104(1):236-50.

15 Atkinson C, Stewart S, Upton PD, Machado R, Thomson JR, Trembath RC, Morrell NW. Primary pulmonary hypertension is associated with reduced pulmonary vascular expression of type II bone morphogenetic protein receptor. Circulation 2002;105(14):1672-8

16 Geraci MW, Moore M, Gesell T, Yeager ME, Alger L, Golpon H, Gao B, Loyd JE, Tuder RM, Voelkel NF. Gene expression patterns in the lungs of patients with primary pulmonary hypertension: a gene microarray analysis. Circ Res 2001;88(6):555-62. 